\title{
Q. Adis
}

a Wolters Kluwer business

\section{This material is the copyright of the original publisher. Unauthorised copying and distribution is prohibited.}

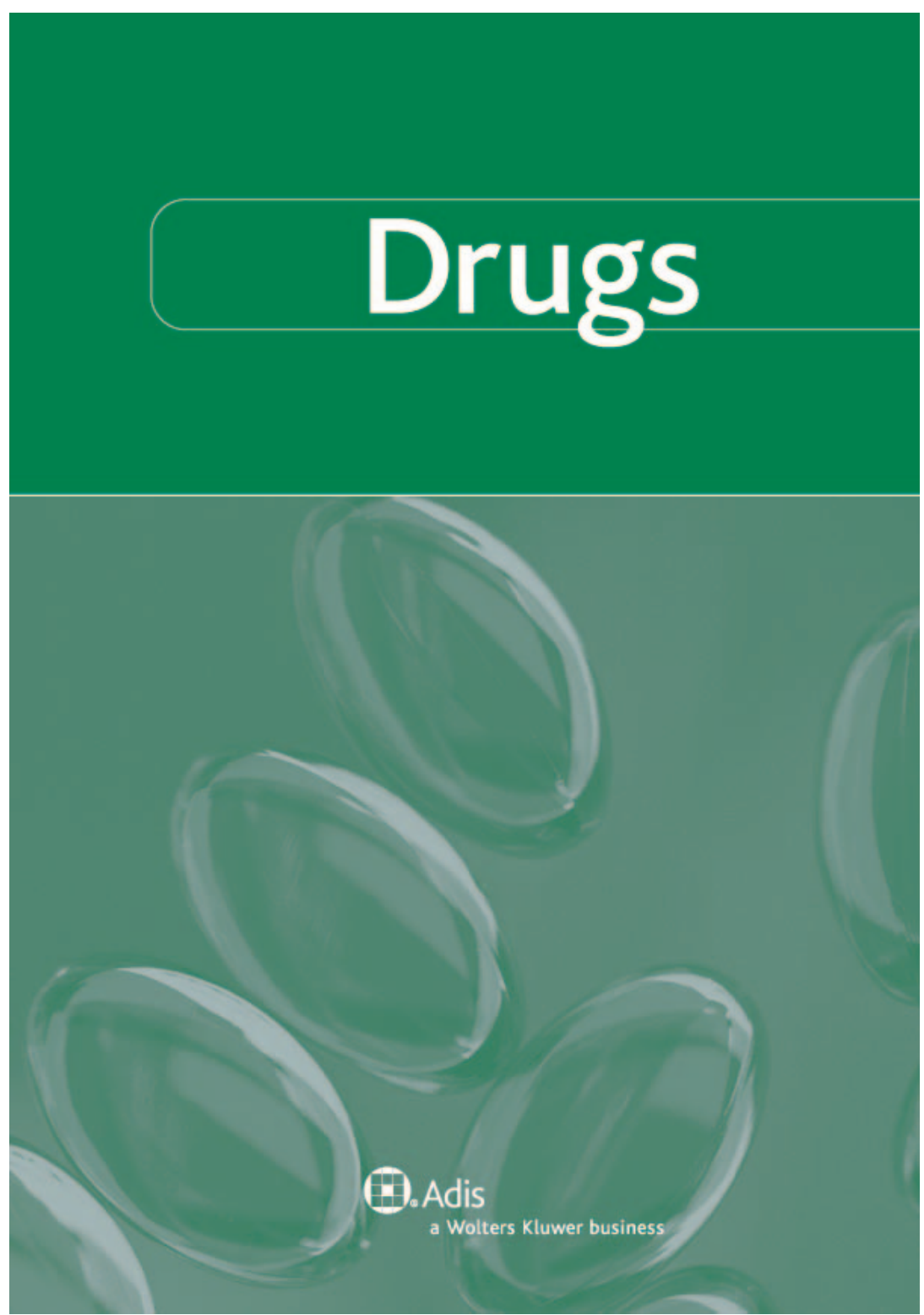

\section{Terms and Conditions for Use of PDF}

The provision of PDFs for authors' personal use is subject to the following Terms \& Conditions:

The PDF provided is protected by copyright. All rights not specifically granted in these Terms \& Conditions are expressly reserved. Printing and storage is for scholarly research and educational and personal use. Any copyright or other notices or disclaimers must not be removed, obscured or modified. The PDF may not be posted on an open-access website (including personal and university sites).

The PDF may be used as follows:

- to make copies of the article for your own personal use, including for your own classroom teaching use (this includes posting on a closed website for exclusive use by course students);

- to make copies and distribute copies (including through e-mail) of the article to research colleagues, for the personal use by such colleagues (but not commercially or systematically, e.g. via an e-mail list or list serve);

- to present the article at a meeting or conference and to distribute copies of such paper or article to the delegates attending the meeting;

- to include the article in full or in part in a thesis or dissertation (provided that this is not to be published commercially). 


\section{Use of Economic Evaluation in Decision Making Evidence and Recommendations for Improvement}

\section{Steven Simoens}

Research Centre for Pharmaceutical Care and Pharmaco-economics, Katholieke Universiteit Leuven, Leuven, Belgium

Information about the value for money of a medicine as derived from an economic evaluation can be used for decision-making purposes by policy makers, healthcare payers, healthcare professionals and pharmaceutical companies. This article illustrates the use of economic evaluation by decision makers and formulates a number of recommendations to enhance the use of such evaluations for decision-making purposes.

Over the last decades, there has been a substantial increase in the number of economic evaluations assessing the value for money of medicines. Economic evaluation is used by policy makers and healthcare payers to inform medicine pricing/reimbursement decisions in more and more countries. It is a suitable tool to evaluate medicines and to present information about their value for money to decision makers in a familiar format. In order to fully exploit the use of economic evaluation for decision-making purposes, researchers need to take care to conduct such economic evaluations according to methodologically sound principles. Additionally, researchers need to take into account the decision-making context. They need to identify the various objectives that decision makers pursue and discuss how decision makers can use study findings to attain these objectives.

These issues require further attention from researchers, policy makers, healthcare payers, healthcare professionals and pharmaceutical companies with a view to optimizing the use of economic evaluation in decision making.

Medicines have made a significant contribution to improving patient health, ${ }^{[1]}$ but decision makers are concerned about the costs of medicines in addition to their effectiveness. ${ }^{[2]}$ Thus, decision makers seek instruments that can aid the implementation of safe and effective medicines that support further health improvements whilst containing pharmaceutical expenditure. Economic evaluation provides a tool to assess whether a medicine adds sufficient value for money to justify its costs. To this effect, an economic evaluation con- ducts a comparative analysis of at least two health technologies in terms of both their costs and outcomes. ${ }^{[3]}$ The technique of economic evaluation can be applied to any technology in healthcare, but this paper focuses specifically on medicines.

In principle, information about the value for money of a medicine as derived from an economic evaluation can be used for decision-making purposes by a variety of stakeholders. Policy makers can use economic evaluation to inform the allocation of scarce healthcare resources. Healthcare 
payers can apply evidence about the value for money of medicines to inform pharmaceutical pricing/reimbursement decisions. Healthcare professionals can rely on economic evaluation to shed light on alternative approaches to managing a specific disease. Finally, pharmaceutical companies can employ techniques such as economic evaluation to demonstrate the value for money of their medicines. This implies that the use of economic evaluation in decision making is situated at the central level, the local level and the patient level. ${ }^{[4]}$ Overall, the application of economic evaluation to medicines fits within a trend towards evidence-based decision making in healthcare. ${ }^{[2]}$

This article asks the following question: in practice, does economic evaluation of medicines provide useful information for decision-making purposes? It illustrates the use of economic evaluation by decision makers and formulates a number of recommendations to enhance the use of such evaluations for decision-making purposes.

\section{Use of Economic Evaluation in Decision Making}

The strength of economic evaluation is corroborated by the dramatic increase in the number of published economic evaluations assessing the value for money of medicines in recent decades. For instance, the Tufts Medical Center CostEffectiveness Analysis Registry, which includes more than 2000 cost-utility analyses of health technologies published since 1976, shows that the number of cost-utility analyses of medicines has risen exponentially over time (see figure 1). ${ }^{[5]}$ Also, specific databases have been developed that contain information about economic evaluations of medicines and other health technologies (e.g. the Health Economic Evaluations Database at McMaster University [Hamilton, Ontario, Canada $]^{[6]}$ and the National Health Service [NHS] Economic Evaluation Database at the University of York [York, UK] ${ }^{[7]}$ ).

The use of economic evaluation in decision making derives from the fact that economic evaluation provides a tool to evaluate medicines and enables decision makers to maximize population health subject to a budget constraint. An economic evaluation serves to demonstrate the value for money of a medicine. For instance, in order to gain access to the market, medicines need to overcome a number of so-called hurdles. A new medicine needs to demonstrate its quality (first hurdle), safety (second hurdle) and efficacy (third

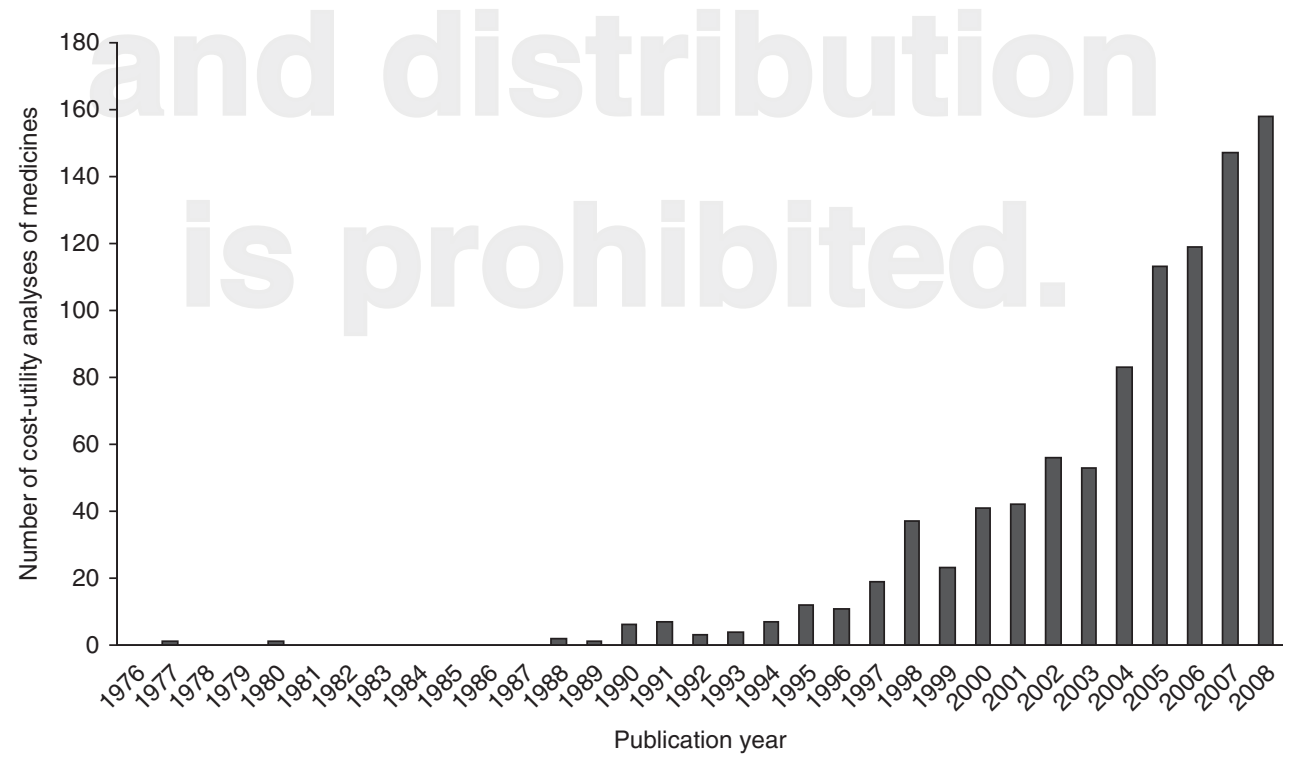

Fig. 1. Trend in cost-utility analyses of medicines, 1976-2008. ${ }^{[5]}$ 
Table I. Use of economic evaluation in decision making around the world

\begin{tabular}{|c|c|c|}
\hline Country & Organization & Implementation date \\
\hline Australia & Pharmaceutical Benefits Advisory Committee ${ }^{[8]}$ & 1993 \\
\hline Belgium & Medicine Reimbursement Committee ${ }^{[9]}$ & 2002 \\
\hline England and Wales & National Institute for Health and Clinical Excellence ${ }^{[10]}$ & 1999 \\
\hline France & High Health Authority ${ }^{[11]}$ & 2008 \\
\hline Germany & Institute for Quality and Efficiency in Health Care ${ }^{[12]}$ & 2007 \\
\hline Netherlands & Health Care Insurance Board ${ }^{[13]}$ & 1999 \\
\hline New Zealand & Pharmaceutical Management Agency ${ }^{[14]}$ & 1993 \\
\hline Scotland & Scottish Medicines Consortium ${ }^{[15]}$ & 2002 \\
\hline Sweden & Dental and Pharmaceutical Benefits Agency ${ }^{[16]}$ & 2002 \\
\hline Taiwan & Centre for Drug Evaluation ${ }^{[17]}$ & 2008 \\
\hline
\end{tabular}

hurdle) with a view to obtaining a registration. Pricing/reimbursement may depend on the value for money of the medicine at the time of the application (fourth hurdle) and after a number of years following access to the market (fifth hurdle). Information gained from economic evaluations is used to inform pricing/reimbursement decisions in an increasing number of countries (see table I).$^{[8-17]}$ Medicines that provide better value for money are rewarded by means of a more favourable price/ reimbursement.

The results of an economic evaluation can be expressed in the form of an incremental costeffectiveness ratio (ICER). ${ }^{[18]}$ This ratio relates the difference in costs between a medicine and the comparator to the difference in outcomes. An often used outcome measure of health-related quality of life is quality-adjusted life-years (QALYs). The QALY takes into account the quantity and quality of life. The quality of life associated with a health state is measured through the use of health utilities. A utility reflects the preference of an individual for the health state. Utilities are elicited on a scale of 0 (reflecting death) to 1 (reflecting perfect health). Quality-of-life data are then combined with estimates of the time period for which the health benefits last to generate QALYs. The results of an economic evaluation using QALYs are expressed by means of the following:

$$
\operatorname{ICER}=\left(\mathrm{C}_{1}-\mathrm{C}_{0}\right) /\left(\mathrm{Q}_{1}-\mathrm{Q}_{0}\right)
$$

where $\mathrm{C}_{1}$ is the cost of the medicine; $\mathrm{C}_{0}$ is the cost of the comparator technology; and $\mathrm{Q}_{1}$ and $\mathrm{Q}_{0}$ are the number of QALYs associated with the medicine and the comparator, respectively.

For instance, an economic evaluation estimated that sunitinib generated 0.2 additional QALYs as compared with best supportive care in Ireland. ${ }^{[19]}$ With an additional cost of $€ 13456$ as compared with best supportive care, sunitinib had an ICER of $€ 57280$ per QALY (2005 values).

The ICER of an economic evaluation can then be compared with a threshold value for money, which reflects the maximum cost per unit of outcome that society or a healthcare payer is willing to pay for a medicine. This threshold approach was originally proposed by Weinstein and Zeckhauser ${ }^{[20]}$ in 1973. These authors considered the case of a healthcare payer who could fund some, but not all, medicines due to a budget constraint. It can be shown that, if medicines are ranked from the lowest to the highest ICER, health can be maximized by selecting medicines with increasing ratios until the budget is exhausted. The ratio of the last medicine (i.e. the medicine with the highest cost per unit of outcome ratio) to be selected is called the threshold ratio.

Table II provides an overview of threshold ICERs in selected countries. ${ }^{[21-27]}$ For instance, the National Institute for Health and Clinical Excellence (NICE) in England and Wales uses a threshold value for money of $£ 20000$ per QALY, although medicines with a cost-utility ratio above this threshold can be recommended for use in the NHS if there is a strong case to do so. ${ }^{[28]}$ This may apply to orphan medicines (i.e. medicines used to treat rare diseases), end-of-life medicines in 
Table II. Examples of threshold incremental cost-effectiveness ratios

\begin{tabular}{|c|c|c|}
\hline Country & Threshold value in local currency & Threshold value in $€^{a}$ \\
\hline Australia $^{[21]}$ & \$A42 000-76 000 per life-year & $€ 24700-44700$ per life-year \\
\hline Canada $^{[22]}$ & \$Can20 000-100 000 per QALY & $€ 12700-63300$ per QALY \\
\hline England/Wales ${ }^{[23,24]}$ & $£ 20000-30000$ per QALY & $€ 22800-34100$ per QALY \\
\hline Netherlands ${ }^{[25]}$ & $€ 20000-80000$ per QALY & $€ 20000-80000$ per QALY \\
\hline Scotland $^{[26]}$ & $£ 20000-30000$ per QALY & $€ 22800-34100$ per QALY \\
\hline $\mathrm{USA}^{[27]}$ & \$US50 000 per QALY & $€ 34400$ per QALY \\
\hline
\end{tabular}

oncology and medicines used to treat paediatric diseases. Nevertheless, a review of NICE's guidance issued between 1999 and 2005 concluded that health technologies having a ratio exceeding $£ 30000$ per QALY were unlikely to be recommended. ${ }^{[23]}$ Judgements about what is regarded as an (un)acceptable ICER are made by NICE's advisory committees, which consist of clinicians and health managers working in the NHS, statisticians, health economists and patients. ${ }^{[24]}$

However, there is a debate about whether the use of thresholds is informative. For instance, a recent report by the Belgian Health Care Knowledge Centre (KCE) has reviewed the methodological challenges of the threshold approach and fundamental discussions about the meaning of value for money. ${ }^{[2]}$ Other approaches (i.e. replacement approach, programme budgeting and marginal analysis) have focused on improving resource allocation, rather than maximizing health subject to a budget constraint. Alternatively, the generalized optimization framework and multi-criteria decision analysis make it possible to consider other criteria in addition to value for money. A detailed discussion of the (dis)advantages of the threshold approach and alternative approaches falls outside the scope of this article, but can be found in the literature. ${ }^{[30]}$

\section{Enhancing the Use of Economic Evaluation in Decision Making}

Decision makers appreciate the need to evaluate projects in terms of their costs and benefits. As economic evaluation in essence evaluates the costs and benefits of a medicine, economic eval- uation offers a framework that presents information about medicines in a format that is familiar and useful to them. For this purpose, two conditions need to be satisfied. Such information will only be useful to decision makers insofar as it has been derived from a methodologically sound assessment of a medicine. Furthermore, economic evaluation needs to explicitly consider the decision-making context.

\subsection{The Methodology of Economic Evaluation}

An economic evaluation needs to be conducted according to methodological standards. Therefore, organizations such as the International Society for Pharmacoeconomics and Outcomes Research have developed and disseminated multiple methodological guidelines on the conduct of economic evaluations. Nevertheless, the fact that the conduct of an economic evaluation may not be straightforward has been amply demonstrated in the case of, for example, orphan medicines, ${ }^{[31]}$ biopharmaceutical medicines ${ }^{[32]}$ and pharmaceutical care services (i.e. the delivery by the pharmacist of medicines with a view to improving medicine use and enhancing health outcomes in collaboration with other healthcare professionals and the patient). ${ }^{[33]}$

Although decision makers are likely to embrace the principle of weighing costs and benefits in making decisions about medicines, their actual knowledge of economic evaluation techniques is generally limited and they have doubts about the methodological quality of studies. ${ }^{[34]}$ It has been argued that decision makers tend to 'accommodate' rather than 'assimilate' the information derived from an economic evaluation by developing 
new conceptual schemes to understand the new knowledge. ${ }^{[35]}$ This is witnessed in a survey in which decision makers in nine European countries questioned the understandability and credibility of economic evaluation. ${ }^{[36]}$ Therefore, there is a need to educate and train decision makers on economic evaluation techniques.

Economic evaluation is a relatively young scientific discipline that has existed for about 40-50 years. As a result, there are still a number of methodological uncertainties surrounding the technique of economic evaluation itself. ${ }^{[3]}$ Furthermore, existing economic evaluations of medicines do not always meet methodological standards due to factors such as the limited expertise of researchers, data limitations and practical constraints. This is, for example, noted by studies reviewing the growth and quality of pharmaceutical economic evaluations. ${ }^{[37,38]}$ In response to this, specific databases have been developed that assess the quality of economic evaluations of medicines and other health technologies (e.g. the NHS Economic Evaluation Database at the University of York ${ }^{[7]}$ ). Uncertainty over the quality of economic evaluations undermines their use in and applicability to decision making. Additional efforts need to be made to further develop, standardize and rigorously apply the methodology of economic evaluation.

The results of an economic evaluation of a medicine are inherently uncertain (as is also the case for studies investigating the safety, efficacy or effectiveness of medicines). Although an economic evaluation generally generates a single ICER to inform a decision, sensitivity analyses are usually also carried out to explore the robustness of results to changes in input parameters. Current methods of exploring uncertainty in economic evaluation have developed rapidly in the last 10 years and are arguably more sophisticated than those adopted typically when considering clinical effectiveness. Decision makers may struggle to handle the fact that economic evaluation does not generate a single or uniform answer to the question of the value for money of a medicine. Rather than interpreting this as a drawback of economic evaluation, in my opinion this is actually an advantage: in this way, decision makers obtain a comprehensive picture of how the value for money of a medicine changes under different circumstances.

Economic evaluation may serve to inform medicine pricing/reimbursement decisions at a national level. However, such information may be less relevant to the local decision-making context. ${ }^{[39]}$ The issues of generalizability and transferability of results to the local context need to be addressed in any economic evaluation. An economic evaluation is generalizable if it can be applied without adjustment to another decision-making context, whereas an analysis is transferable if it can be adapted to apply to another decisionmaking context. In this respect, the following question needs to be asked: to what extent did the characteristics of the national/regional/local healthcare system influence the value for money of a medicine? In other words, does the decision-making context have an impact on the value for money of a medicine? To address this issue, good research practices have recently been developed for dealing with aspects of generalizability and transferability. ${ }^{[40]}$

\subsection{The Decision-Making Context of Economic Evaluation}

This section describes several aspects of the decision-making process that restrict the usefulness of economic evaluations, such as the timeliness, funding, transparency and practical relevance of economic evaluations; institutional features of the healthcare system; the rational use of medicines in daily practice; and decision-making criteria. A number of avenues to overcome these barriers are outlined.

Decision makers are often confronted with the need to make a decision in the short-term. A decision needs to be taken in the absence of relevant information from an economic evaluation or when there is insufficient time to carry out an economic evaluation. For instance, a retrospective analysis explored the time lag between the publication of effectiveness data and the publication of cost-effectiveness evidence used in 30 medicine appraisals published by NICE in England and Wales by October 2001. The mean time lag was estimated to be 3.2 years. ${ }^{[41]}$ 
To address the issue of timeliness of economic evaluation, institutions such as the Belgian $\mathrm{KCE}$ and NICE in England and Wales have introduced rapid assessment procedures for determining the value for money of new medicines. Since September 2009, all new medicines in Ireland are subjected to a rapid review by the National Centre for Pharmacoeconomics in collaboration with the Health Service Executive (Tilson and Barry ${ }^{[42]}$ ). This process takes approximately $2-4$ weeks and considers such factors as the patient population, available alternative technologies, budget impact, price, effectiveness and cost-effectiveness data from other jurisdictions. Generally, the modalities of a rapid assessment as opposed to a traditional economic evaluation may differ between institutions, but a rapid assessment typically is conducted within a shorter timeframe, is likely to have a more specific focus, may draw on industry input, and may be restricted to a review of the economic literature or to an economic evaluation based on a limited primary data collection. ${ }^{[43]}$

Alternatively, decision makers can resort to innovative mechanisms involving temporary or conditional reimbursement. For instance, the US Centers for Medicare and Medicaid Services have issued guidance on so-called 'coverage with evidence development', which offers interim reimbursement of a medicine subject to further evidence being generated on its cost effectiveness. ${ }^{[4]}$ Another example concerns risk-sharing arrangements. ${ }^{[45]}$ Under such a scheme, the pharmaceutical company shares the risk with the third-party payer that the medicine may not be effective for a particular patient. If the medicine does not have the expected effect, the company may lose some or all product revenue, or needs to provide a replacement product.

The development of mechanisms of temporary or conditional reimbursement has important consequences for economic evaluation, since the decision will be revisited on the basis of the cost effectiveness of the medicine in daily real-life practice (e.g. where compliance is less than perfect, where patients often have co-morbidities, etc.). Often these studies are based on observational designs in contrast to the experimental designs used in phase II and III trials. They pose specific methodological challenges because biases have to be accounted for when analysing observational data.

The results of economic evaluation matter to pharmaceutical companies as evidence on the value for money of a medicine may be used to inform pricing/reimbursement decisions. A systematic review of 494 English-language cost-utility analyses found that studies funded by industry were more likely to report ICERs below the threshold value for money. Studies sponsored by industry were also more likely to be of lower methodological quality and to be published in scientific journals with lower impact factors. ${ }^{[46]}$ Similarly, a retrospective analysis of economic evaluations submitted to NICE observed that ICERs calculated by industry were significantly lower than those computed by academics. ${ }^{[47]}$

Guidelines standardizing the conduct of economic evaluations may help to curtail possible bias in economic evaluations. For instance, the Belgian $\mathrm{KCE}$ has issued guidelines that industry needs to adhere to when preparing medicine reimbursement applications that involve an economic evaluation. ${ }^{[48]}$ Furthermore, the Belgian Medicine Reimbursement Committee employs an internal team of experts who assess the quality of such medicine reimbursement applications. Generally, agencies make use of an internal team (e.g. the Scottish Medicines Consortium), a team of experts from several independent academic centres (e.g. NICE in England and Wales) or an academic team (e.g. the Pharmaceutical Benefits Advisory Committee in Australia). Finally, it should be noted that this issue of potential bias in industrysponsored economic evaluations does not apply to those countries where economic evaluations are conducted by independent organizations (e.g. Canada, the UK).

Decision makers tend to be concerned about the lack of transparency in the reporting of economic evaluations of medicines. ${ }^{[4]}$ In response to this, many countries have specified exhaustive standard frameworks or templates for the presentation of economic evaluations. In some countries, this reporting framework goes as far as stipulating approaches for the economic models on which the evaluation is based. The full economic 
evaluation model needs to be submitted in electronic form to reimbursement authorities in, for example, Belgium. Also, international groups such as the Grading of Recommendations Assessment, Development and Evaluation Working Group $(\text { GRADE })^{[49]}$ are involved in producing simple summary frameworks for effectiveness and costeffectiveness information, an approach that has been adopted by other organizations such as the Scottish Intercollegiate Guidelines Network (SIGN). ${ }^{[50]}$ However, current reporting formats may still not meet the needs of busy decision makers with little training in economic evaluation. A recent study explored the preferences of 84 decision makers for the reporting of economic evaluation information. The findings showed that decision makers preferred a very short summary, plus a more extensive format should they wish to consult the economic evaluation in more detail. ${ }^{[51]}$ Also, a literature review has suggested that personal contact between researchers and decision makers is a major factor facilitating the use of economic evaluation evidence in decision making. ${ }^{[52]}$

Specific institutional features of the healthcare system may inhibit the usefulness of information provided by an economic evaluation of a medicine. For instance, in many countries health expenditure is divided across several budgets and it may be difficult to transfer funds between budgets. Also, there may be a tendency for decision makers to adopt a budget silo mentality. ${ }^{[53]}$ This means that decision makers consider each budget separately, but do not take account of the full impact of a medicine across budgets. This budget silo mentality poses challenges for economic evaluation because medicines are likely to have an impact on multiple budgets. For instance, although the introduction of a new medicine may add to the pharmaceutical budget, this may be accompanied by reduced expenditure on other health services utilization. This silo mentality not only applies to budgets within the healthcare system, but also to the budget of the healthcare system and other sectors of the economy (e.g. a medicine may increase the pharmaceutical budget but reduce productivity loss). Therefore, there is a need to overcome the budget silo mentality in order to enhance the value for money of economic eval- uation for decision-making purposes by means of techniques such as programme budgeting and marginal analysis. ${ }^{[54]}$

Economic evaluations of medicines need to report findings that have practical relevance. For instance, savings arising from fewer hospitalizations are accounted for as a financial benefit in an economic evaluation. However, the benefit does not necessarily materialize in a real-life setting as vacated beds may be used in the treatment of other patients. If this is the case, researchers are essentially taking into account freed resources, whereas decision makers have an interest in actual financial savings. ${ }^{[4]}$ In an economic evaluation, freed-up bed days may allow the treatment of more patients (providing more benefits at presumably increased cost). The value put on freed-up bed days should reflect the value of the opportunity to use freed-up bed days for this other use. A related point is that even if freed-up bed days were not used for another purpose, actual financial savings would only accrue if staff can be made unemployed, wards closed down, etc. In the short-term, this is unlikely to happen.

Nevertheless, this case shows that it is important for researchers to understand the point of view of decision makers, to ascertain for what purpose decision makers wish to use the information derived from the economic evaluation, and to present the results accordingly. To this effect, researchers need to explicitly report their methodological choices, such as, for instance, the perspective of the economic evaluation (e.g. society, healthcare system, health insurance fund, hospital) and the time horizon of the evaluation, so that decision makers can correctly interpret and apply the results of the economic evaluation.

Decision makers are increasingly aware that a yes or no decision about reimbursement of a medicine does not ensure that it is appropriately used in daily practice. Therefore, some countries have implemented various reforms to encourage the rational use of medicines. For instance, Swedish counties have implemented measures such as the establishment of drug and therapeutic committees, the development of therapeutic guidelines, academic detailing, continuous benchmarking of prescribing patterns, the imposition of prescribing 
targets in high-profile disease areas, the development of quality indicators and financial incentives. ${ }^{[55]}$

In practice, decision makers are likely to consider multiple criteria when making medicine decisions. In some countries, healthcare payers are required by law to base decisions on a set of predefined criteria. For instance, New Zealand's Pharmaceutical Management Agency applies nine decision criteria that include health needs, availability of other treatments, clinical benefits and risks, and budgetary impact, amongst other things. Also, in some countries, decisions are ultimately taken by a specific committee such as the Medicine Reimbursement Committee in Belgium. This committee consists of representatives from universities, health insurance funds, professional societies of physicians and pharmacists, the pharmaceutical industry and government ministries. Committee members may act as advocates of particular interests, bringing into play other decision criteria in addition to the value for money of a medicine. For instance, in the British NHS, members of local decision-making committees have been noted to defend sectional, organizational or departmental interests. ${ }^{[56]}$ If a decision is taken not to fund a medicine that provides value for money, then the availability of an economic evaluation forces decision makers to justify their decision and to state the criteria on which the decision is based. In this way, the use of economic evaluation supports the consistency and transparency of decision making.

\section{Conclusions}

Economic evaluation can be used by policy makers, healthcare payers, healthcare professionals and pharmaceutical companies to ascertain the value for money of medicines. It is a suitable tool to evaluate medicines and to present information about their value for money to decision makers in a familiar format. In order to fully exploit the use of economic evaluation for decision-making purposes, researchers need to take care to conduct such economic evaluations according to methodologically sound principles. Additionally, researchers need to take into account the decision-making context. They need to identify the various objectives that decision makers pursue and discuss how decision makers can use study findings to attain these objectives.

\section{Acknowledgements}

Financial support for this research project was received from Pharma.be, the Belgian association of the innovative pharmaceutical industry. The sponsor was not involved in the study design; the collection, analysis and interpretation of data; the writing of the manuscript; or the decision to submit the paper for publication. The author has no conflicts of interest that are relevant to the content of this manuscript.

\section{References}

1. Grootendorst P, Pierard E, Shim M. Life-expectancy gains from pharmaceutical drugs: a critical appraisal of the literature. Expert Rev Pharmacoecon Outcomes Res 2009; 9 (4): 353-64

2. Perleth M, Jakubowski E, Busse R. What is 'best practice' in health care? State of the art and perspectives in improving the effectiveness and efficiency of the European health care systems. Health Pol 2001 Jun; 56 (3): 235-50

3. Drummond M, Sculpher MJ, Torrance GW, et al. Methods for the economic evaluation of health care programmes. 3rd ed. Oxford: Oxford University Press, 2005

4. Drummond M, Brown R, Fendrick AM, et al. Use of pharmacoeconomics information: report of the ISPOR Task Force on use of pharmacoeconomic/health economic information in health-care decision making. Value Health 2003 Jul; 6 (4): 407-16

5. Centre for the Evaluation of Value and Risk in Health. The Tufts Cost-Effectiveness Analysis Registry [online]. Available from URL: https://research.tufts-nemc.org/cear/default. aspx [Accessed 2010 Apr 16]

6. McMaster University. Health Economic Evaluations Database [online]. Available from URL: http://ibrary.mcmaster. $\mathrm{ca} /$ articles/health-economic-evaluations-database [Accessed 2010 Apr 16]

7. Centre for Reviews and Dissemination. National Health Service Economic Evaluation Database [online]. Available from URL: http://www.york.ac.uk/inst/crd/ [Accessed 2010 Apr 16]

8. Pharmaceutical Benefits Advisory Committee [online]. Available from URL: http://www.health.gov.au/internet/ main/publishing.nsf/Content/Pharmaceutical+Benefits+Ad visory+Committee-1 [Accessed $2010 \mathrm{Jul} 27$ ]

9. Medicine Reimbursement Committee [online]. Available from URL: http://www.riziv.fgov.be/drug/nl/drugs/decisions_ report/report_crm_cgt/index.htm [Accessed 2010 Jul 27]

10. National Institute for Health and Clinical Excellence [online]. Available from URL: http://www.nice.org.uk [Accessed $2010 \mathrm{Jul} 27$ ]

11. High Health Authority [online]. Available from URL: http://www.has-sante.fr/portail/jcms/j_5/accueil [Accessed 2010 Jul 27]

12. Institute for Quality and Efficiency in Health Care [online]. Available from URL: http://www.iqwig.de [Accessed 2010 Jul 27] 
13. Health Care Insurance Board [online]. Available from URL: http://www.cvz.nl [Accessed 2010 Jul 27]

14. Pharmaceutical Management Agency [online]. Available from URL: http://www.pharmac.govt.nz [Accessed $2010 \mathrm{Jul}$ 27]

15. Scottish Medicines Consortium [online]. Available from URL: http://www.scottishmedicines.org.uk/smc/CCC_First Page.jsp [Accessed 2010 Jul 27]

16. Dental and Pharmaceutical Benefits Agency [online]. Available from URL: http://www.tlv.se/in-english [Accessed $2010 \mathrm{Jul} 27]$

17. Center for Drug Evaluation, Taiwan [online]. Available from URL: http://www.cde.org.tw/eng/default.html [Accessed $2010 \mathrm{Jul} 27]$

18. Simoens S. Health economic assessment: a methodological primer. Int J Environ Res Public Health 2009; 6 (12): 2950-66

19. National Centre for Pharmacoeconomics. A review of the costeffectiveness of sunitinib $\left(\right.$ Sutent $\left.{ }^{\circledR}\right)$ under the High Tech Drug Scheme in Ireland [online]. Available from URL: http:// www.ncpe.ie/u_docs/doc_129.pdf [Accessed 2010 Jul 27]

20. Weinstein MC, Zeckhauser R. Critical ratios and efficient allocation. J Public Econ 1973; 2: 147-57

21. George B, Harris A, Mitchell A. Cost-effectiveness analysis and the consistency of decision making: evidence from pharmaceutical reimbursement in Australia (1991 to 1996). Pharmacoeconomics 2001; 19: 1103-9

22. Laupacis A, Feeny D, Detsky AS, et al. How attractive does a new technology have to be to warrant adoption and utilization? Tentative guidelines for using clinical and economic evaluations. CMAJ 1992; 146: 473-81

23. Raftery J. Review of NICE's recommendations, 1999-2005. BMJ 2006; 332: 1266-8

24. Rawlins MD, Culyer AJ. National Institute for Clinical Excellence and its value judgments. BMJ 2004; 329: 224-7

25. Health Care Insurance Board. Richtlijnen voor farmacoeconomisch onderzoek [guidelines for pharmaco-economic research]. Amstelveen: Health Care Insurance Board, 1999

26. Webb D. Early assessment of cost-effectiveness. Congress of the European Association for Clinical Pharmacology and Therapeutics; 2009 Jul 12-15; Edinburgh

27. Grosse SD. Assessing cost-effectiveness in healthcare: history of the $\$ 50000$ per QALY threshold. Expert Rev Pharmacoecon Outcomes Res 2008; 8: 165-78

28. National Institute for Health and Clinical Excellence. The guidelines manual 2009. London: National Institute for Health and Clinical Excellence [online]. Available from URL: http://www.nice.org.uk/aboutnice/howwework/de velopingniceclinicalguidelines/clinicalguidelinedevelopment methods/GuidelinesManual2009.jsp [Accessed 2010 Jul 28]

29. Cleemput I, Neyt M, Thiry N, et al. Thresholds for costeffectiveness in health care. Brussels: Belgian Health Care Knowledge Centre, 2008

30. Simoens S. How to assess the value of medicines? Frontiers Pharmacoeconomics Health Outcomes. In press

31. Drummond M, Evans B, LeLorier J, et al. Evidence and values: requirements for public reimbursement of drugs for rare diseases. A case study in oncology. Can J Clin Pharmacol 2009; 16 (2): e273-81

32. Simoens S. Health economics of market access for biopharmaceuticals and biosimilars. J Med Econ 2009 Sep; 12 (3): $211-8$
33. Simoens S, Laekeman G. Applying health technology assessment to pharmaceutical care: pitfalls and future directions. Pharm World Sci 2005 Apr; 27 (2): 73-5

34. Galani C, Rutten FF. Self-reported healthcare decisionmakers' attitudes towards economic evaluations of medical technologies. Curr Med Res Opin. Epub 2008 Sep 29

35. Traulsen JM, Klinke BO. Using health technology assessment to put pharmaceutical care on the political agenda. Pharm World Sci 2004 Apr; 26 (2): 61-3

36. Hoffmann C, Graf von der Schulenburg JM. The influence of economic evaluation studies on decision making: a European survey. The EUROMET Group. Health Pol 2000 Jul; 52 (3): 179-92

37. Neumann PJ, Fang C, Cohen J. 30 years of pharmaceutical cost-utility analyses: growth, diversity, and methodological improvement. Pharmacoeconomics 2009; 27 (10): 861-72

38. Neumann PJ, Greenberg D, Olchanski NV, et al. Growth and quality of the cost-utility literature, 1976-2001. Value Health 2005 Jan-Feb; 8 (1): 3-9

39. Eddama O, Coast J. A systematic review of the use of economic evaluation in local decision-making. Health Pol 2008 May; 86 (2-3): 129-41

40. Drummond M, Barbieri M, Cook J, et al. Transferability of economic evaluations across jurisdictions: ISPOR Good Research Practices Task Force Report. Value Health 2009 Jun; 12 (4): 409-18

41. Stoykova B, Drummond M, Barbieri M, et al. The lag between effectiveness and cost-effectiveness evidence of new drugs: implications for decision-making in health care. Eur J Health Econ 2003 Nov; 4 (4): 313-8

42. Tilson L, Barry M. Recent developments in Pharmacoeconomic evaluation in Ireland. Expert Rev Pharmacoecon Outcomes Res 2010; 10 (3): 221-4

43. Vinck I, Neyt M, Thiry N, et al. A procedure for the assessment of new medical devices. KCE reports 44A ed. Brussels: Belgian Health Care Knowledge Centre, 2006

44. Tunis SR, Pearson SD. Coverage options for promising technologies: Medicare's 'coverage with evidence development'. Health Aff 2006; 25: 1218-30

45. Cook JP, Vernon JA, Manning R. Pharmaceutical risksharing agreements. Pharmacoeconomics 2008; 26: 551-6

46. Bell CM, Urbach DR, Ray JG, et al. Bias in published cost effectiveness studies: systematic review. BMJ 2006 Mar; 332 (7543): 699-703

47. Miners AH, Garau M, Fidan D, et al. Comparing estimates of cost effectiveness submitted to the National Institute for Clinical Excellence (NICE) by different organisations: retrospective study. BMJ 2005 Jan; 330 (7482): 65

48. Cleemput I, Van WP, Vrijens F, et al. Guidelines for pharmaco-economic evaluation in Belgium. Brussels: Belgian Health Care Knowledge Centre, 2008

49. GRADE Working Group [online]. Available from URL: http://www.gradeworkinggroup.org/ [Accessed $2010 \mathrm{Jul} 27$ ]

50. SIGN [online]. Available from URL: http://www.sign.ac. uk/ [Accessed $2010 \mathrm{Jul} 27]$

51. Thurston SJ, Craig D, Wilson $\mathrm{P}$, et al. Increasing decisionmakers' access to economic evaluations: alternative methods of communicating the information. Int $\mathbf{J}$ Technol Assess Health Care 2008; 24 (2): 151-7 
52. Innvaer S, Vist G, Trommald M, et al. Health policy-makers' perceptions of their use of evidence: a systematic review. J Health Serv Res Policy 2002 Oct; 7 (4): 239-44

53. Drummond M, Jonsson B. Moving beyond the drug budget silo mentality in Europe. Value Health 2003 Jul; 6 Suppl. 1: S74-7

54. Mitton CR, Donaldson C. Setting priorities and allocating resources in health regions: lessons from a project evaluating program budgeting and marginal analysis (PBMA). Health Policy 2003; 64: 335-48

55. Wettermark B, Godman B, Andersson K, et al. Recent national and regional drug reforms in Sweden: implications for pharmaceutical companies in Europe. Pharmacoeconomics 2008; 26 (7): 537-50

56. Williams I, McIver S, Moore D, et al. The use of economic evaluations in NHS decision-making: a review and empirical investigation. Health Technol Assess 2008 Apr; 12 (7): iii, ix-x, 1-175

Correspondence: Professor Dr Steven Simoens, Research Centre for Pharmaceutical Care and Pharmaco-economics, Katholieke Universiteit Leuven, Onderwijs en Navorsing 2 Herestraat 49, PO Box 521, 3000 Leuven, Belgium. E-mail: steven.simoens@pharm.kuleuven.be
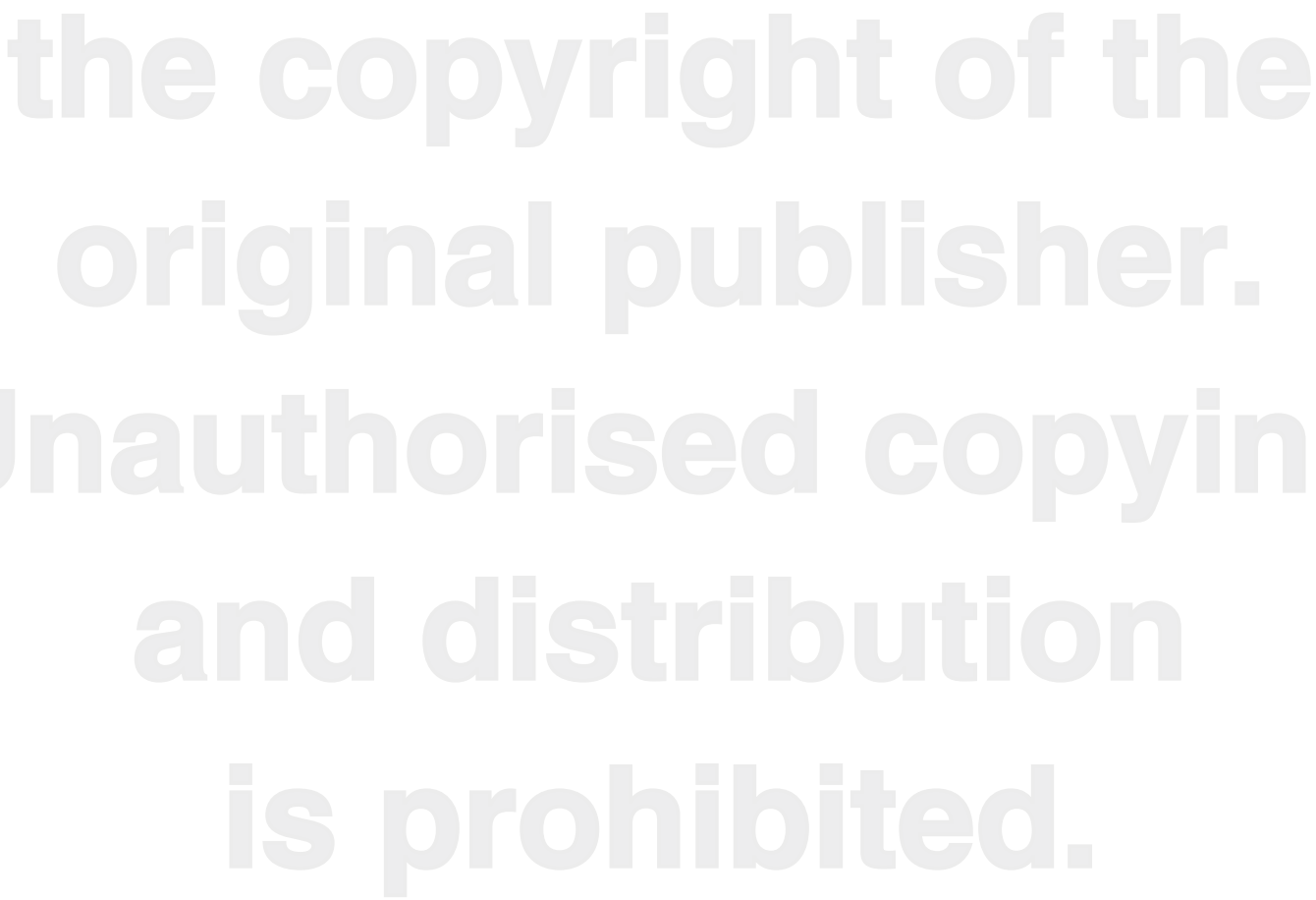